Business \& Economics | Tony Marshall

\section{Social enterprises}

Essential players in sustainable social development?

Creating the strong social bonds that are essential to achieving high levels of social cohesion cannot be left to pure commercial interests or interventions by civil authorities, either local or national. Tony Marshall and June-ho Jang from Anyang studied the role that social enterprises - committed to achieving both profit and socia objectives - play in developing social cohesion in the rapidly developing city of Anyang.

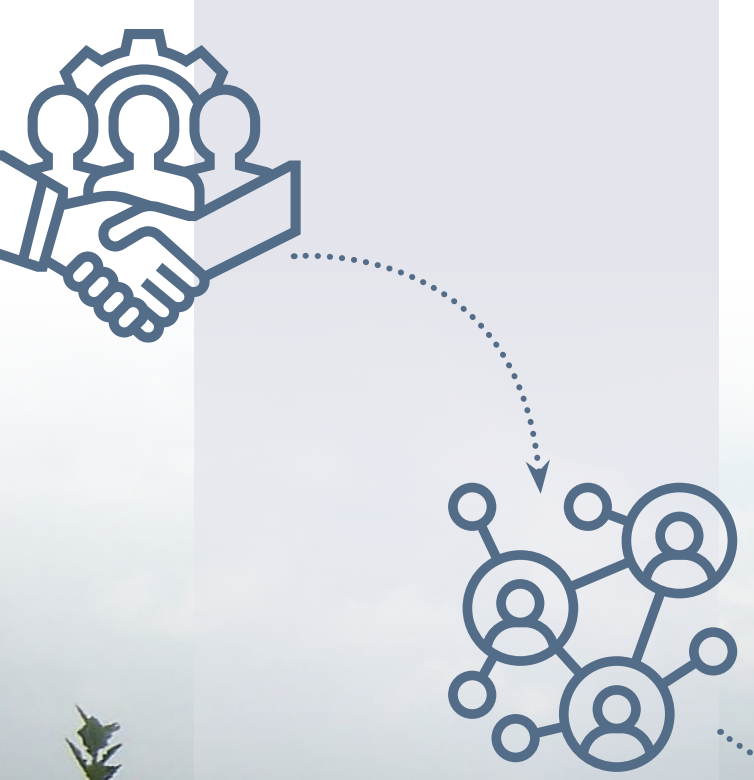

outh Korea, like many Asian nations, is in the process of a rapid mix of rural agrarian and industrialised mix of rural agrarian and industrialised economies to an increasing focus on
high technology-based industry, with the high technology-based industry, with the population drawn to the growing urba rapidly emerging city of Anyang.

Located in the province of Gyeonggi-do, just $21 \mathrm{~km}$ south of the nation's capital, Seoul, Anyang is a city of some 600,000 residents occupying 220,000 homes. It
is ranked 20" in South Korea in terms of size and like many other emerging cities, it is struggling to absorb the influx of new residents. The 'growing pains' of Anyang have been felt across all strata of this evolving society, especially given the 'overflow' from nearby Seoul. Many continue to exchange rural simplicity and its attendant hardships for urban complexity, with new aspirations closely tied to the promise of the city.

The achievements of Hong Kong, Singapore, Thailand, and Bhutan have Asia for achieving (sia for achioving 'Social cohesion is often described as the 'capacity of a society to ensure members, minimising

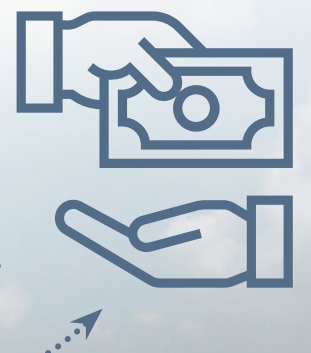

disparities and avoiding marginalisation (Europe, 2008). The Anyang city
authorities, supported by national policies, have made achieving these same As such, they have fully embraced the power of modern digital communication not not only to achieve a cohesive society modern 'smartcity'.

Tony Marshall and June-ho Jang from Anyang University South Korea, investigated how modern

communications, particularly digita
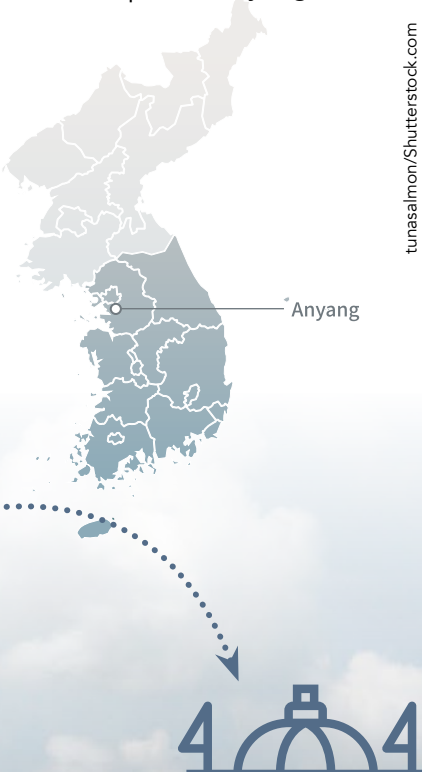
कित्व चाचा benchmarks of social cohesion a priority.

and internet-based technologies, are harnessed to collect data on the chas as Anyang Responsive a smartcity can use the extensive data (much of it avilable in real-time for functions such as public transport for example) to adjust quickly in the short term and to fail tate planning for the longer term.

\section{SOCIAL COHESION}

However, it is easy to talk about such concepts as social cohesion, sustainable development, and smart infrastructure, but what do these terms really mean for those involved? Tony Marshall and June-ho Jang have provided a broad description of what social cohesion looks like in a moder city and what is required to ensure that progress in this area is truly sustainable.

The key element, from the definition bove, is ensuring the wellbeing of all the people who make up

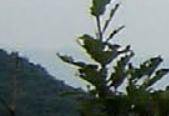

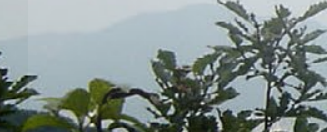
. artibiloces city. One indicator of social cohesion is the lack of social unrest, a goal for all civin

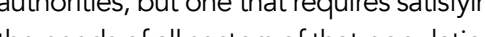
particularly in our modern world of rapid mass communication.

Social cohesion requires members of a society to cooperate with each oth to survive and prosper. In turn, this cooperation facilitates the formulation of partnerships and increases the chances of individuals achieving their aspirations. This is further enabled by the willingness of other societal elements to cooperate and share the fruits of their endeavours equitably. At a micro-level (such as the individual or family unit) we often describe this as 'social capital', but social cohesion positicly evolving les of socia capit.

respect and networks of trustin relationships between people who orinstitis gradients in society' (Claridge 2013).

As these three elements evolve . and strengthens.

\section{SUSTAINABILITY}

, for long term sustainable of a city, continuing positive social cohesion requires initiatives and policies chat recognise the changes and new

challenges that will appear.

In practice, sustainability in urban development can also be broken down
into three keys elements:

The team investigated how modern communications are harnessed to collect data on the infrastructure performance of a smart city such as Anyang.

Ultimately, social cohesion can be considered to have three primary ingredients: bonding, bridging and linking.

- Bonding - described as horizontal ties between individuals within specific social groups (typically demographic, ethnic, and shared interests for example), as opposed to ertical ties

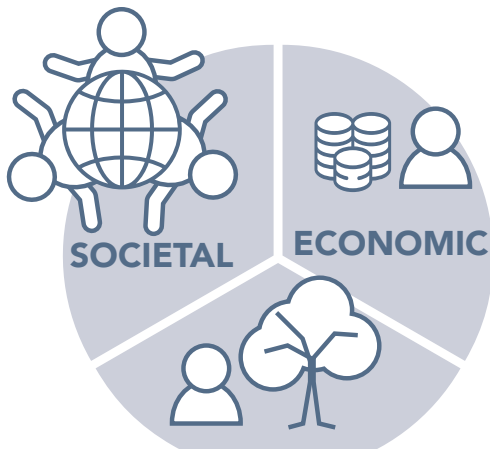
ENVIRONMENTAL

- Bridging - describes both ties between those specific social groups horizontally and also includes the immediate ties evolve informally, such as mutual trust and respect.

- Linking - is similar to bridging. However it focuses on the 'norms

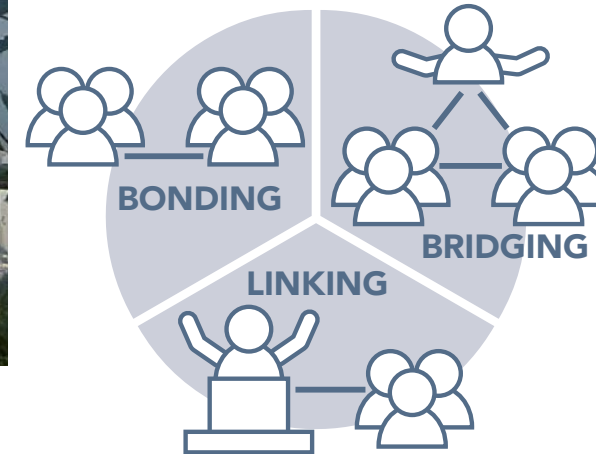

Societal - preserving the universal values of 'equity, peace, and tranquillity', where equity implies equal access to all those values.

-Economic - opportunities to satisfy the needs, wants, and aspirations of individuals living in a modern society must be available to all, through the enable the purchase of goods.

Environmental - economic priorities the natural environment. At the heart of this environmental element is the conservation of natural resources and development and the building of should not be met at the expense of 
a role in further supporting it, ultimately
it is the ability of SEs to become selfit is the ability of SEs to become selffunding through profitable trade that development Social enterprises ara according to Marshall and Jang 'the commissioners of [a] sharing economy'. However, important questions remain, particularly with regard to the effectiveness and efficiency with which SEs fulfili their declared mission.

\section{THE STUDY}

In their study, Marshall and Jang sought to use the insights gained in the experience of development in Anyang to provide a broader and more nuanced understanding of the role of SEs in urban sustainability. Through a survey of over 1,000 participants in 18 ditferent business areas of Anyang, Marshall collected with data relating to specifice oxper cial enterprises.

The most frequent response was recognising the roles SEs play in economic development by supporting those groups disadvantaged by issues relating to employment and spending power (with awareness of this role at $60.4 \%$ ). However, less understanding was shown regarding SE's engagement with, and contribution to, the social and environmental elements of urban sustainable development (with. awareness of these issues at around $47.4 \%$. needs of relatively small popu fall through the gaps in the "big pict need equally specific and complex groups both with a more equitable place in the society, and the currency toi with that society. These groups those who are disabled, people out of simply, profit driven business the sources of income that enable economic activity. Civil authorties, on the oher hand, which are diven by social health, education,

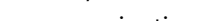

and housing

- that ensures

is available to

businesses and

organisations that

need labour.

Important questions remain, particularly Itwasfound with regard to the effectiveness and stakeholders efficiency with which social enterprises appear less likely to fulfil their declared mission. peers in addressing challenges that

\section{SOCIAL ENTERPRISE (SE)}

In reality, Anyang's residents are, like most rapidly growing urban developments, prone to multiple negative externalities and impacts. The 'rewards' promised by urban development are seldo 'equitably' available across the population, even considering the basics of housing, education, and healthcare. As the authors explain: 'The government is struggling to address socioeconomic challenges due to mismaches between employment opponunices, atordable retall products, and the
quality public goods."
While the charitable sector still plays a role, the responsibility is increasingly being
occupied by the hybrid model of social enterprises: businesses that generate their funds through the profits of trading with an over-arching purpose of inclusivity for their target group. This will typically provide jobs and tailored services, with a overall goal of giving the groups access to the social and economic benefits that optimise, as much as possible, the Although government may help to social enterpine, and bureation of individuals' active participation in society. less generally recognised. The study vitally cohesion, as South Korea has one of the highest average life expectancies in the world at nearly 82 years, together with unemployment currently at $4.2 \%$, in a tota population of 51 million (2020).

The authors recommend further research, expanded to more cities, to build a more thorough understanding of how the work of social enterprises in the areas of education, society, and the vevironment can contribute to the many urban development. highlights the critical importance of social

\section{Behind the Research}

Tony Marshall

E: amarsha1914@hotmail.com T: $+82-10-5169-1914$
W: wwwhresearchgate net/profile/Tony-Marshall-3

\section{Research Objectives}

Tony Marshall and June-ho Jang examine the role that teveloping social cohesion in the rapidly developing city of Anyang.

\section{Detail}

Tony Marshall is currently a PhD student in urba Anyang University, where he is student of the doctor of urban planning programme. He currently holds two undergraduate degrees from the University of Arkansas (landscape architecture and computer science), and two master's degrees from Virginia Tech (architecture and technology education)

\section{Funding}

Anyang University and Diverse Horizons, Inc.

Collaborators

The nation of South Korea, the citizens of South Korea, Anyang University, The City of Anyang, Anyang citizen

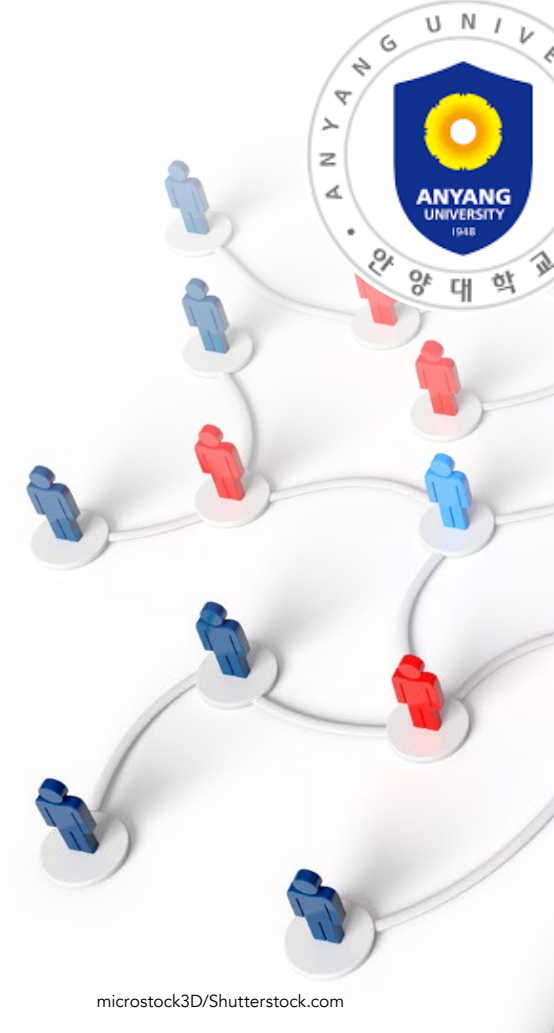

\section{References}

Marshall, T and Jang, J-h (2020). The Role of Socia Enterprises in Urban Sustainability: Insights from Anyang urbansci4030042

Council of Europe (2008). Report of High-Level Task Force on Social Cohesion: Towards an Active, Fair and Socially Cohesive Europe.

Claridge, T (2013). Explanation of types of social capital Social Capital Research. Ionlinel Social Capital Research. Available at: https://www.socialcapitalresearch.com/ explanation-types-social-capital [Accessed 10 Sept 2021].

\section{Personal Response}

Do you think the inferior levels of awareness for social and environmental $S E$ activity are associated with low

II In my humble opinion, I think the South Kor society is a reactive society; meaning they Kore mor practical than theoretical in the way they live their lives. Lower levels of information were not an issue because the various focuses of the social enterprises investigated were clearly explained to the participants in the first of interest one could make an argument that interest levels could be associated with the economic sector that the participant a fliliated themselves with at the time of performing the survey. 